\title{
UNA ORDALÍA ATRIBUIDA AL REY SALOMÓN EN UN APÓCRIFO ÁRABE CRISTIANO
}

\author{
Juan Pedro Monferrer-Sala \\ Universidad de Córdoba \\ ff1mosaj@uco.es
}

\section{RESUMEN}

La versión árabe del Testamento de Salomón incluye un texto sobre una ordalía de reminiscencias bíblicas en la que el monarca debe finalmente impartir justicia ante la acusación de fornicio contra una joven. Se trata de un texto interesante en la tradición árabe cristiana, no tanto por la rareza del mismo, sino sobre todo por la dimensión y características narrativas del relato, cuya fuente es $\mathrm{Nm}$ 5,11-31, con referencias a Lc 10,38-42, o en su defecto a Jn 12,2.

Palabras ClaVE: Testamento de Salomón, ordalía, cristianismo, apócrifo, tradición árabe cristiana.

\section{AN ORDEAL ATTRIBUTED TO KING SOLOMON \\ IN A CHRISTIAN ARABIC APOCRYPHON}

\section{ABSTRACT}

The Arabic version of the Testament of Solomon includes a text about an ordeal of biblical reminiscences in which the monarch must finally impart justice as a consequence of the accusation of fornication against a young woman. This is an interesting text in the Christian Arabic tradition, not so much for the rarity of it, but above all for the dimension and narrative

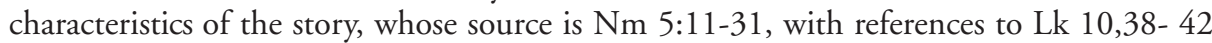
or Jn 12:2.

KeY WORDS: Testament of Solomon, ordeal, Christianism, apocryphon, Christian Arabic tradition.

\section{INTRODUCCIÓN}

Son varias las recensiones griegas que hasta el momento nos han llegado (Duling, 1983-85: I, 935-987, Duling, 1988: 87-112) de una obra griega conocida como "Testamento de Salomón" (McCown, 1922: 10-28; Delatte, 1927: 211-227; Klutz, 2005: 19-34). Además del material griego, también conocemos una recensión árabe con ese mismo título, Ahkām Sulaymān ("Sentencias de Salomón”) del que 
ahkām se refiere a sentencias de tipo jurídico-sapiencial atribuidas en la tradición bíblica y apócrifa al rey Salomón (Parker, 1992: 75-91; Klutz, 2005: 75-79), como lo evidencia el 'Libro de la Sabiduría' (Fichtner, 1939: 155-192).

La diversidad fuentística de la versión árabe depende del texto bíblico: 1 Re 2,12; 3,4-5.6-9.11-13.15.16-21.22-28; 4,24.31.34; 8-9; 10,1-13; 11-14; 2 Re 5,7 y par. (Porter, 1967: 93-128), conjugado con material apócrifo, hagádico y otro procedente de las Antiquitates de Flavio Josefo (Klutz, 2005: 58-73). La lengua del texto original, pese a que Gaster pensó en un original hebreo, parece ser el griego (McCown, 1922: 42, 38-43, 108-111).

Las dificultades que plantean los manuscritos griegos para establecer la historia del texto se complican aún más en el caso de la versión árabe, conservada en los manuscritos Ar. 214/6 (fols. 186-203) de la Bibliothèque Nationale de France y Vaticano arabo 448 (fols. 29'-54') de la Biblioteca Apostolica Vaticana, que representan una tradición textual genuinamente árabe que ha dado lugar a una versión ex novo.

La recepción de la obra en el medio árabe e islámico fue deficiente y hubo de llegar a través de canales judeocristianos (McCown, 1922: 94; Bagatti, 1972: 151-160; Torijano, 2002: 175-178). La tradición textual griega del "Testamento", que de suyo constituye un tratado demonológico en toda regla, ha dado paso en la recensión árabe a una obra de carácter narratológico en el que el elemento demonológico, aunque básico para el sostenimiento del hilo narrativo, queda ya en un elemento meramente anecdótico: los nombres de los demonios, salvo un caso concreto, han sido eliminados y la larga lista de demonios que transmite la tradición manuscrita de la versión griega del "Testamento de Salomón" ha quedado reducida a la indefinición en el caso árabe, en la que la figura de Salomón y sus hechos legendarios (Abramsky-Sperling, 2007: 758-759) se ha superpuesto sobre el tratado demonológico que centra el interés de la tradición textual griega. Es más, la versión árabe ha prescindido de la escasa presencia angelológica que figura en la tradición textual griega.

El contenido de la versión árabe, aunque relacionada con la griega, contiene una estructura completamente distinta. Mientras que para la tradición textual griega la estructura queda supeditada a la actuación de las diversas figuras demonológicas y obviamente a la actuación del rey Salomón, en la versión árabe tenemos una unidad total, orgánica del texto desde el punto de vista estructural en la que una breve introducción y una conclusión, aún más breve, actúan como proemio y epílogo del texto. A su vez, el desarrollo narrativo se sucede armónicamente por medio de espacios narrativos, independientes unos de otros.

La versión árabe consta de tres cuadros narrativos. El nudo central de la obra, tal vez la sección más antigua, está construido por un topos central, la construcción del Templo de Jerusalén, sobre el que fueron articulados el resto de secciones, cuyo elemento articulador es la demonología, presente en las expansiones, donde el referente marco es la erección del Templo. La versión árabe, además, responde a la tipología literaria apócrifa del "testamento" con un ensamblaje de varios desarrollos narrativos, independientes entre sí, que han sido unidos mediante transiciones breves en tercera persona.

En la introducción, elaborada a partir del texto bíblico, el narrador sitúa a Salomón frente al Templo de Jerusalén, que da paso directo al primer cuadro 
narrativo: la conocida disputa de las dos mujeres, en el texto dos prostitutas, por la posesión del niño que ha quedado con vida.

El segundo cuadro, que es el que centra el interés de este trabajo, trata del tema de la capacidad de impartir justicia en los litigios por parte del rey Salomón. Frente al primer texto al que acabamos de referirnos, en el que Salomón debe hacer justicia ante la reclamación de dos mujeres, sin embargo en el segundo texto es un auditorio más amplio, el pueblo $(s h a ' b)$, al que va dirigido el asunto.

Se trata de una historia sencilla, perfectamente estructurada en la que los personajes intervinientes, el pueblo, el sacerdote, Marta, Salomón, Joaquín y María, ofrecen un cuadro de alta dinamicidad narrativa gracias a los diálogos que articulan la narración. Además, tenemos una serie de transiciones narrativas, con las que el autor expansiona el texto mediante procedimientos de naturaleza hagádica que dan lugar a un texto de tipo ejemplificativo sobre la ordalía de los celos. Tanto la primera como la segunda historia exhiben una relación con el mundo de la prostitución, con el que la figura de Salomón guarda cierta relación.

Con el final de este segundo cuadro, y sin transición, el autor pasa a la sección central de la obra: la construcción del Templo de Jerusalén y el poder y el dominio concedidos por Dios al rey Salomón sobre los demonios mediante un sello/anillo (khātam < $\sigma \varphi \rho \alpha \gamma i ́ s)$ y el nombre inefable que se encuentra grabado en dicho sello.

\section{EL TEXTO}

La versión árabe de este texto sobre la ordalía nos presenta a Salomón en una situación en la que debe hacer justicia, concretamente en ante un caso de acusación de fornicación del que es acusada Marta (Martä), quien junto con su hermana de María (Maryam) es hija de un tal Joaquín (Yuwāqìm).

En las líneas que siguen ofrecemos la versión castellana del texto árabe (Monferrer Sala, 2006: 49-55, 134-138), con la anotación de aquellos aspectos que resulten de interés.

Había en Jerusalén un varón llamado Joaquín' ${ }^{1}$ que tenía dos hijas, dos hermanas: el nombre de la mayor era Marta y el de la menor María ${ }^{3}$. (La hermana mayor) era hermosa y humilde, tenía ojos penetrantes, mas no había en ella maldad ni rencor y su corazón era recto. Su hermana menor, María, era perversa, estaba llena de rencor y de maldad y estaba seria a toda hora ${ }^{4}$. No acostumbraba a sonreír nunca y siempre iba acicalada.

${ }^{1}$ Yuwāqìm < heb. Yěhōyāqìm ("Yahweh erigirá"), que no corresponde a ninguno de los tres mencionados en el Antiguo Testamento.

${ }^{2}$ Martā < aram. martã ("señora").

${ }^{3}$ Maryam < heb. Miryam, de etimología incierta.

${ }^{4}$ Lit.: "y su rostro serio en todo momento". 
En aquel tiempo hallaron unos a un pequeñuelo abandonado a la puerta del templo del Señor, al que habían dejado para que (alguien) lo criase. Entonces dijo la gente: - «¿Quién ha hecho esto?».

$\mathrm{Y}$ (unos) arguyeron diciendo:

- «¿Con quién lo hizo esta ramera? Como (figura) en la Ley de Moisés ${ }^{5}$, pues escrito está en la Ley: al que encontrareis fornicando sea lapidado hasta morir ${ }^{6}$ y sea (luego) quemado ${ }^{\star}$.

Reuniéndose el pueblo y yendo hasta el sacerdote ${ }^{8}$ le dijeron:

- «Esta ramera ¿en casa de quién estaba?».

El sacerdote les respondió:

- «La ramera que he visto estaba en la casa de Joaquín».

Cuando se difundió entre todo el pueblo esta noticia -esto que se creía de Marta, la hija mayor de Joaquín, porque ellos la veían de ojos penetrantes, reírse mucho y que de nadie se ocultaba- se congregó el pueblo ante el rey Salomón y le dijeron: - «:Señor nuestro, rey!, haz llamar a Joaquín, tráelo a nuestra presencia a este lugar, porque el sacerdote ha dicho que esta ramera estaba en su casa».

El rey Salomón (lo) mandó llamar y trayendo a Joaquín le dijo (que estaba allí) por su hija, pues era ramera y (por ello) merecedora de ser lapidada y quemada, como (prescribe) la Ley de Dios.

Entonces dijo Joaquín:

- «iMi señor el rey!, han dado falso testimonio de mi hija, han hablado de ella por doquier, quieren darle muerte y también el sacerdote ha mentido sobre ella, porque vio a mi hija adornándose; por ello, ¡mi señor el rey!, ha dicho esto de ella. Pero que sea conjurada por el agua, démosle a beber en el monte (pues de haber cometido este adulterio, moriría en el monte) y no regrese a su casa otra vez. Si quedase pura de esta fornicación que vuelva a su casa sin que haya en ella tacha (alguna), como (prescribe) la Ley'. Cuando quedare libre de esta falsedad, que juzguen y el rey haga que persevere esta palabra».

Y avanzó hasta el sacerdote para que (la) conjurara sobre (el) agua y le diese a ella a beber en el monte. El sacerdote se puso delante del altar ${ }^{10}$ de Dios y extendiendo sus manos dijo ${ }^{11}$ :

- «iTú, Marta hija de Joaquín!, si fornicaste con (alguien de)l pueblo de Dios, bebe de esta agua, que Dios mostrará su poder sobre ti y sobre todo aquel del pueblo de Israel que haya fornicado (contigo)».

${ }^{5}$ Nämüs Müsä, que refiere la Torah, donde nāmūs procede del siriaco namūsōo <r. vó Fraenkel, 1886: 278. El antropónimo árabe Mūsā es calco del heb. Mōšěh (cf. Horovitz, 1925: 156).

${ }^{6}$ Cf. Dt 22,22; además Jn 8,5.

Cf. Lv 20,14; 21,19.

${ }^{8}$ Kähin, forma cognada de heb. kōhẹn y del aram.-sir. kōhen / kōhnō (cf. Mingana, 1927: 85).

${ }^{9}$ Cf. Nm 5,11-31.

${ }^{10}$ Madhbah refiere un altar destinado a sacrificios (cf. Beeston, Ghul, Müller, Ryckmans, 1982: 38), característico de los sacrificios sangrantes practicados por los semitas (De Vaux, 1964; De Vaux, 1985: 55, 528-548), con presencia en el ámbito cultual preislámico (Ryckmans, 1951: 32-33).

${ }^{11}$ Cf. Nm 5,19-22. 
El sacerdote derramó el agua acusatoria ${ }^{12}$ y la hizo ir al monte. Llegado el día tercero regresó a su casa y no le sobrevino mal [alguno]. El pueblo quedó asombrado de ello y dijeron que el que hubiera testimoniado falsamente que muriese ${ }^{13}$. En ese instante el sacerdote fue merecedor de morir de acuerdo con la Ley de Moisés. Entonces dijo Salomón a los principales de los hijos de Israel:

- «El sacerdote vio a esta ramera en la casa de Joaquín, pero ésta, Marta, vivió al beber de esta agua acusatoria. Sé que lo que vio el sacerdote es correcto y no hay en ello falsedad (alguna). También yo la pondré a prueba otra vez con el agua con la que fue conjurada, de acuerdo con lo que soñó el sacerdote, porque esto es lo que él recuerda de la casa de Joaquín».

Entonces se levantó Salomón, se detuvo delante del templo de Dios y colocó el agua en una magnífica vasija grande, diciendo al pueblo:

- «Vosotros habéis empujado a esta joven ${ }^{14}$ a morir injustamente, pues su falta no ha quedado patente ante vosotros, porque vosotros testimoniasteis contra ella con falsedad».

El pueblo contestó:

- «iSeñor nuestro, rey!, ni su falta ha quedado patente ante nosotros ni hemos testimoniado falsamente contra ella, ni este asunto nos concierne, ni nosotros somos los que la hemos puesto a prueba, sino que este asunto es (cosa) del sacerdote: él es el que lo refirió».

El rey Salomón dijo:

- «Llorad sobre esta alberca y que las lágrimas de vuestros ojos caigan hasta el agua que hay en ella, mezclándose con el agua».

Haciendo como les ordenase el rey, después de esto extendió el rey sus manos, oró sobre la alberca y juró sobre ella por el nombre majestuoso ${ }^{15}$ diciendo:

- « ¿Dios de los ejércitos ${ }^{16}$, ¡Dios!, ¡Dios de la verdad! muestra la verdad en el agua que hay en esta alberca y si Marta hubiese fornicado (si bien (pudiera ser que) no) quede llena de lepra ${ }^{17}$, como está prescrito en la Ley, mas si fuere inocente y pura quede sana de esta agua y de cuanta agua beba de la que hay en esta alberca mediante la que se pone a prueba ${ }^{18}$. Si estuviere enferma toda su piel sea llena de lepra

${ }^{12} \mathrm{Al}$-mä' al-mudda'à corresponde al heb. mè ha-marim ("las aguas amargas", lit. "de las amar-

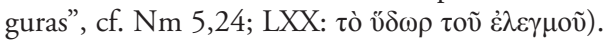

${ }^{13}$ Cf. Nm 5,23-28; Dt 19,18-21.

${ }^{14}$ Lit.: "hija pequeña".

${ }^{15}$ Sobre el potencial los teóforos en la producción mística judía (Grözinger, 1987: 53-69).

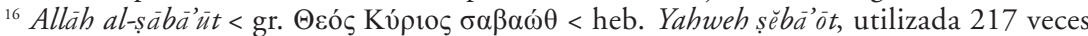
en el Antiguo Testamento, es tradicionalmente interpretada como "Yahweh de los ejércitos". El plural abstracto femenino șěbàōt aparece con frecuencia en fórmulas exorcísticas (Naveh, Shaked, 1985: 40-41, 56-57, 94-95, 96, 102-103, 180-181; Betz, 1986: 12), abunda en los textos gnósticos (cf. Labib, Coptic Gnostic 1956: I, 398) y es frecuentemente citado tanto en las invocaciones coptas como en los apócrifos etiópicos de procedencia cristiana (Aešcoly, 1932: 124).

${ }^{17}$ Barass < heb. șâra'at ("lepra"), designaba tanto a la lepra como a diversas afecciones cutáneas que entrañaban impureza cultual, cf. Lv 13-14; 2 Re 5,7.

${ }^{18}$ Cf. $\mathrm{Nm} \mathrm{5,} 24$. 
de pies a cabeza. Si estuviere limpia de pecado que (ningún) mal la aflija. Y ahora, ¡Señor mío, Dios mío!, si Marta fuere pura no se manifieste en ella pecado (alguno) delante del pueblo para que cuando la vean tengan temor de tu nombre, ¡Señor!, porque tú eres Dios de toda alma ${ }^{19}$ y nadie es como tú. Por medio de esta agua, que está en la alberca, son mostrados todos los pecados para que no regrese nadie, ¡oh Señor!, que haya fornicado entre tu pueblo. Si estuviere libre de este fornicio que han proferido de ella, manifiéstalo ¡oh Dios! y bendice a esta niña a la que han acusado".

Cuando el rey Salomón terminó de orar sobre el agua de la alberca ordenó que trajesen el fuego y la leña para -si al meterse en el agua saliese llena de lepra- ser quemada viva como está (prescrito) en la Ley de Moisés.

Luego, el rey dijo a Marta, la hija de Joaquín:

- «iVen!, baja hasta el fondo del agua».

Al momento se desnudó y despojándose de sus vestidos descendió hasta el fondo de la alberca y sumergiéndose siete veces en el agua salió sin que apareciese en ella (ningún signo de) lepra. Todos sus parientes y cuantos estaban con ella se alegraron porque estaba sana. Cuando llegó (donde estaban todos) María besó a Marta, pues fue ella la que cometió el fornicio, quedando toda su boca llena de lepra blanca ${ }^{20}$ como la nieve ${ }^{21}$. Los miembros de María que tocaron a Marta se llenaron de lepra por el agua que había sido conjurada. Al ver lo sucedido, todo el pueblo de Israel se estremeció y se asombró y gritando todos ellos dijeron:

- «Gloria al Señor de los ejércitos!».

Entonces el rey ordenó que cogiesen a María y la quemasen en el fuego, como está (prescrito) en la Ley de Dios. Todo el pueblo supo que fue ella la que cometió este fornicio en Israel. Y temieron al rey Salomón ${ }^{22}$, porque todas sus acciones eran puestas a prueba por el agua con la que conjuraba y dijeron:

- «En verdad, este rey es el que instaurará la generación de la salvación ${ }^{23}$ ».

Éste es el segundo juicio que hizo Salomón, el rey de Israel y de Jerusalén.

\section{NOTA FINAL}

La ordalía del agua, una prueba relacionada con el juicio divino, pretendía servir para decidir la culpabilidad o inocencia de una acusada. En el texto bíblico, el único pasaje que se refiere a una prueba de ordalía es $\mathrm{Nm}$ 5,11-31 en el que

${ }^{19}$ Nasamah, cognado del heb.-aram. nëshämah.

${ }^{20}$ Baraș abyad es una interpretación del heb. baheret, un tipo de "mancha blanca" que se producía por erupción en la piel y que parecía ser un indicio de lepra, cf. Lv 13,2.4.19.23.

${ }^{21}$ Cf. $\mathrm{Nm} 5,27$.

${ }^{22}$ El tema de la reputación y atribución a Salomón de prácticas exorcistas y otras modalidades de ejercicio de los poderes mágicos gozó de enorme predicamento en la tradición judía (Klutz, 2005: 80-81).

${ }^{23}$ Qarn khalās, de la que, por mediación de su padre el rey David, llegará el Mesías. 
se alude a una prueba de celos, del que la Mishnah ofrece un marco completo de todo este ritual en Sot 1-7 (Morell, 1999; Perea Yébenes, 2000: 145-153).

Reproducimos debajo la traducción del texto hebreo de Nm 5,11-31, dada la importancia que este tiene para la versión árabe.

${ }^{11}$ Yahweh habló a Moisés y le dijo: ${ }^{12}$ habla a los israelitas y diles: cualquier hombre cuya mujer se haya desviado y le haya engañado, ${ }^{13}$ ha dormido un hombre con ella con relación carnal a ocultas del marido; ella se ha manchado en secreto, no hay ningún testigo, no ha sido sorprendida; ${ }^{14}$ si el marido es atacado de celos y recela de su mujer, que efectivamente se ha manchado; o bien le atacan los celos y se siente celoso de su mujer, aunque ella no se haya manchado; ${ }^{15}$ ese hombre llevará a su mujer ante el sacerdote y presentará por ella la ofrenda correspondiente: una décima de medida de harina de cebada. No derramará aceite sobre la ofrenda, ni la pondrá incienso, pues es "oblación de celos", oblación conmemorativa para recordar una falta. ${ }^{16} \mathrm{El}$ sacerdote presentará a la mujer y la pondrá delante de Yahweh. ${ }^{17}$ Echará luego agua viva en un vaso de barro y tomando polvo del pavimento del Templo, lo esparcirá sobre el agua. ${ }^{18}$ Pondrá el sacerdote a la mujer delante de Yahweh, le descubrirá la cabeza y pondrá en sus manos la oblación conmemorativa, o sea la oblación de los celos. El sacerdote tendrá en sus manos las aguas de maldición y funestas. ${ }^{19}$ Entonces, el sacerdote conjurará a la mujer y le dirá: si no ha dormido un hombre contigo, si no te has desviado ni manchado desde que estás bajo la potestad de tu marido, sé inmune a estas aguas amargas y funestas, ${ }^{20}$ pero si, estando bajo la potestad de tu marido, te has desviado y te has manchado, durmiendo con un hombre distinto de tu marido... ${ }^{21} \mathrm{El}$ sacerdote entonces proferirá sobre la mujer este juramento y dirá el sacerdote a la mujer: que Yahweh te ponga como maldición y execración en medio de tu pueblo, que haga languidecer tus caderas e infle tu vientre. ${ }^{22}$ Que entren estas aguas de maldición en tus entrañas, para que inflen tu vientre y hagan languidecer tus caderas. Y la mujer responderá: jamén, amén!'. ${ }^{23}$ Después el sacerdote escribirá en una hoja estas imprecaciones y las borrará con las aguas amargas. ${ }^{24}$ Hará beber a la mujer las aguas de maldición y funestas, y las aguas funestas entrarán en ella para hacérsele amargas. ${ }^{25}$ El sacerdote tomará entonces de la mano de la mujer la oblación de los celos, mecerá la oblación delante de Yahweh y la presentará en el altar. ${ }^{26} \mathrm{El}$ sacerdote tomará de la oblación un puñado, el memorial, y lo quemará sobre el altar, y le hará beber a la mujer las aguas. ${ }^{27}$ Cuando le haga beber de las aguas, si la mujer está manchada y de hecho ha engañado a su marido, cuando entren en ella las aguas funestas le serán amargas: se inflará su vientre, languidecerán sus caderas y será mujer de maldición en medio de su pueblo. ${ }^{28}$ Pero si la mujer no se ha manchado, sino que es pura, estará exenta de toda culpa y tendrá hijos. ${ }^{29}$ Este es el rito de los celos, para cuando una mujer, después de estar bajo la potestad de su marido, se haya desviado y manchado, ${ }^{30}$ o para cuando un hombre, atacado de celos, recele de su mujer: entonces pondrá a su mujer en presencia de Yahweh y el sacerdote realizará con ella todo este rito. ${ }^{31} \mathrm{El}$ marido estará exento de culpa, y la mujer cargará con la suya.

El texto árabe, que pertenece a ese tipo de ritual al que era sometida la mujer sospechosa de adulterio conocido como "sacrificio de los celos", podemos enmarcarlo en una tipología que podemos calificar como ordalía de tradición bíblica, presente en los textos de Qumrān (Wassen, 2005: 61-68), aunque de recio abolengo 
en el medio semita en general (Greengus, 2011: 53-59). La oración "el sacerdote derramó el agua acusatoria" es, de facto, una modulación de Nm 5,16-18. En ella, además, el autor hace un juego de palabras con el pl. marîm ("(aguas) amargas") y el antropónimo Miryam, que en hebreo se escriben igual (מרים), aunque es improbable que el supuesto autor egipcio haya podido tener acceso a un texto hebreo, con mucho relacionar los términos árabes Maryam (María) y murr ("amargo").

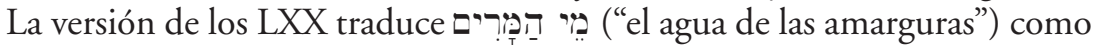

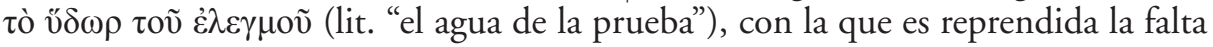
cometida, que además cuenta con un referente en el Protoevangelio de Santiago

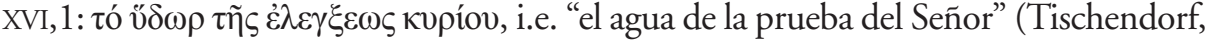


2011: VIII, 126a).

Pero además, el autor del texto árabe, recurre a los nombres de Marta (Martā) y María (Maryam), que tal vez puedan estar inspirados en la narración contenida en Lc 10,38-42 (Smith, Williams, 1999: 103-109) (cf. Jn 12,2), i.e. las hermanas de Lázaro, que llevan esos mismos nombres. En la escena concreta a la que acabamos de aludir Jesús entabla conversación con una de las dos hermanas, Marta, que es descrita como una joven hacendosa y responsable de su casa.

Por otro lado, en lo que se refiere a la alusión al padre de ambas jóvenes en el texto, de nombre Joaquín, esta no se refiere al monarca cuyo reinado es referido en 2 Re 8-20 2, ni al padre de la Virgen María, de acuerdo con la narración que nos proporciona el "Protoevangelio de Santiago" (De Strycker, 1961), que circuló en árabe gracias a las traducciones llevadas a cabo por los traductores melkitas (Monferrer-Sala, 2011:347-380)24. Antes al contrario, como sucede con los nombres de Marta y María, el autor se limita a utilizar estos nombres aprovechando el rendimiento que produce el eco bíblico de los mismos, pero en modo alguno para relacionarlos con ninguno de los textos en los que aparecen.

Obviamente, la narración árabe no es el resultado de adaptar el pasaje lucano (ni de su paralelo joánico tampoco), sino que -en caso de que estemos en lo cierto- el autor del texto árabe tan solo recurre a los nombres de las hermanas de Lázaro como meras referencias nominales conocidas para sus lectores, pero nada más. El texto base es sin duda, $\mathrm{Nm}$ 5,11-31, que el autor adaptó de acuerdo con las necesidades que le exigía no tanto a obra cuanto la necesidad de construir un hilo narrativo introductorio cuya función era la de enfatizar la figura de Salomón y su poder de convicción para resolver conflictos y proclamar veredictos justos.

RECIBIDO: septiembre 2019; ACEPTADO: octubre 2019.

\footnotetext{
${ }^{24}$ Disponemos de una traducción castellana y estudio del texto griego (González Núńez, 1997).
} 


\section{REFERENCIAS BIBLIOGRÁFICAS}

Abramsky, Samuel - S. David Sperling (2007): en Fred. Skolnik (ed.), Encyclopeadia Judaica (2a ed.), 22 vols., Thomson-Gale, Detroit, pp. 755-759.

AEŠCOLY, A.Z. (1932): “Les noms magiques dans les apocryphes chrétiens des éthiopiens”, Journal Asiatique 220: 87-137.

Bagatti, Bellarmino (1972): "I Giudeo-Cristiani e l'Anello di Salomone”, Rivista di Scienze Religiose 60: 151-160.

Beeston, A.F.L., M.A. Ghul, W.W. MÜller, J. Ryckmans (1982): Sabaic Dictionary - Dictionnaire sabéen - al-Mu 'jam al-saba', Publication of the University of Sanaa, Éditions Peeters - Librairie du Liban, Lovaina La Nueva - Beirut.

BETZ, Hans Dieter (1986): The Greek magical papyri in translation. Including the Demotic spells. Volume one: Texts, The University of Chicago Press, Chicago - Londres.

Clines, David J. A. (1993-2011): The Dictionary of Classical Hebrew, 8 vols., Sheffield Phoenix Press, Sheffield.

De STRYCKeR, E. (1961): La forme la plus ancienne du Protévangile Jacques. Recherches sur le Papyrus Bodmer 5 avec une édition critique et une traduction annotée, Subsidia hagiographica 33, Société des Bollandistes, Bruselas.

DE VAuX, Roland (1964): Les sacrifices de l'Ancien Testament, Cahiers de revue Biblique 1, Gabalda, París.

De VAuX, Roland (1985): Instituciones del Antiguo Testamento, versión castellana de Alejandro Ros, Sagrada Escritura 63, Herder, Barcelona.

Delatte, A. (1927): “Testament de Salomon”, Anecdota Atheniensia 36: 211-227.

Duling, Dennis C. (1983-85): “Testament of Solomon”, en James H. CHARLESWORTH (ed.), The Old Testament Pseudepigrapha, 2 vols., Darton Longman \& Todd, Londres, vol. I, pp. 935-987.

Duling, Dennis C. (1988): "The Testament of Solomon: Retrospect and Prospect", Journal for the Study of the Pseudepigrapha 2: 87-112.

Fichtner, J. (1939): "Der AT-Text der Sapientia Salomonis", Zeitschrift für die Alttestamentliche Wissenschaft 57: 155-192.

FraENKEL, Siegmund (1886): Die aramäischen Fremdwörter im Arabischen, E. J. Brill, Leiden.

Greengus, Samuel (2011): Laws in the Bible and in Early Rabbinic Collections: The Legal Legacy of the Ancient Near East, Cascade Books, Eugene, Oregón.

GrÖZINGER, K. E. (1987): "The Names of God and the Celestial Powers: Their Function and Meaning in the Hekhalot Literature", Jerusalem Studies in Jewish Thought 6: 53-69.

Horovitz, Joseph (1925): "Jewish Proper Names and Its Derivatives in the Koran”, Hebrew Union College Annual 2: 145-227.

KLuTz, Todd E. (2005): Rewriting the Testament of Solomon. Tradition, Conflict and Identity in a Late Antique Pseudepigraphon, T\&T Clark International, Londres.

Labib, P. (1956): Coptic Gnostic Papyri in the Coptic Museum at Old Cairo, Government Press, El Cairo.

McCown, Chester Charlton (1922): The Testament of Solomon, Edited from manuscripts at Mount Athos, Bologna, Holkham Hall, Jerusalem, London. Milan, Paris and Vienna, J. C. Hinrichs'sche Buchhandlung, Leipzig.

Mingana, Alfonse (1927): “Syriac Influence on the Style of the Kur'an”, Bulletin of the John Rylands Library 11/1: 77-98. 
Monferrer Sala, Juan Pedro (2006): Testamentum Salomonis Arabicum. Edición, traducción y estudio, Studia Semitica 5, Servicio de Publicaciones de la Universidad de Córdoba, Córdoba.

Monferrer Sala, Juan Pedro (2011): "A Fragmentary Version of the Protevangelium Iacobi Rendered from a Greek Text (Sinai Arabic 535, ca. 13th c.)”, Graeco-Arabica 11: 347-380.

GonZÁlez NúÑEZ, Jacinto (1997): El Protoevangelio de Santiago, Editorial Ciudad Nueva - Fundación San Justino, Madrid.

NAVEH, Joseph, Shaul SHAKED (1985): Amulets and Magic bowls: Aramaic Incantations of Late Antiquity, The Magnes Press, Jerusalén.

PARKER, K. I. (1922): "Solomon as Philosopher King? The Nexus of Law and Wisdom in 1 Kings 1-11", Journal for the Study of the Old Testament 53: 75-91.

Perea Yébenes, Sabino (2000): "Un antiguo ritual mágico semítico: la ordalía del «agua amarga de la maldición»”, en S. PEREA YéBENES, El sello de Dios ( $\Sigma \varphi \rho \alpha \gamma i \varsigma$ $\Theta \varepsilon o \tilde{)})$. Nueve estudios sobre magia y creencias populares greco-romanas, Graeco-Romanae Religionis Electa Collectio 1, Signifer Libros, Madrid, pp. 145-153.

Porter, B. (1967): “The Structure and Theme of the Solomon Narrative (1 Kings 3-11)", Hebrew Union College Annual 28: 93-128.

Ruiz Morell, Olga I. (1999): Las aguas amargas de la mujer. La ordalía de los celos en el rabinismo, Verbo Divino, Estella.

RycKmans, G. (19151): Les religions arabes préislamiques, Bibliothèque du Muséon 26, Publications universitaires, Lovaina.

Smith, Dennis E., Michael E. Williams (1999): New Testament Women, The Storyteller's Companion to the Bible 13, Abingdon Press, Nashville.

VON TISCHENDORF, Konstantin (1853): Evangelia Apocrypha. Adhibitis plurimis codicibus graecis et latinis maximam partem nunc primum consultis atque ineditorum copia insignibus, Avenarius et Mendelssohn, Leipzig.

Torijano, Pablo A. (2002): Solomon the Esoteric King: from King to Magus, Development of a tradition, Supplements to the Journal for the Study of Judaism 73, Brill, Leiden - Boston - Köln.

Wassen, Cecilia (2005): Women in the Damascus Document, Academia Biblica 21, Society of Biblical Literature, Atlanta. 